\title{
Influence of salinity on transport of Nitrates and Potassium by means of the xylem sap content between roots and shoots in young tomato plants
}

Victor M. Gallegos-Cedillo ${ }^{1}$, Miguel Urrestarazu ${ }^{1}$, Juan E. Álvaro ${ }^{2 *}$

${ }^{1}$ Departamento de Agronomía, Universidad de Almería, Almería, España. ${ }^{2}$ Pontificia Universidad Católica de Valparaíso, Escuela de Agronomía, Quillota, Chile. *Corresponding author: juan-eugenio.alvaro@pucv.cl

\begin{abstract}
Salinity is well known to reduce plant growth and yield by reducing water availability; it does so by interfering with both nutrient uptake and translocation. The objective was to determine the nitrate and potassium contents in xylem sap and the root-shoot transportation of both as a function of the salinity of the nutritional solution provided. We compared $\mathrm{NO}_{3}$ - and $\mathrm{K}^{+}$contents and flux in xylem sap collected from cut stems of tomato seedlings, based on electric conductivity (EC) tests among five nutrition solutionsfor soilless crops ranging from medium to high salinity. The EC was 2.2, 3.5, 4.5, 6 and $12 \mathrm{dS} \mathrm{m}^{-1}$. The concentration of nitrates and potassium in the xylem sap remained constant, while the external concentration in the rhizosphere varied greatly. Notwithstanding, the xylematic flux was strongly affected by the salinity of the nutritional solution: at maximum salinity, EC reached $3.5 \mathrm{dS} \mathrm{m}^{-1}$; at minimum, EC was $12 \mathrm{dS} \mathrm{m}^{-1}$. For similar reasons, the longest $\mathrm{NO}_{3}^{-}$and $\mathrm{K}^{+}$transportation distance between root and shoot was achieved when the EC read $3.5 \mathrm{dS} \mathrm{m}^{-1}$, but was reduced by up to $80 \%$ when EC was $12 \mathrm{dS} \mathrm{m}^{-1}$.
\end{abstract}

Keywords: Exudate, root, salinity, sap, Xylem sap flow

\section{Introduction}

From very old to the present, the salinity is one of the most serious environmental stresses limiting growth and yield of horticultural plants (Rameeh, 2012; Mastrogiannidou et al., 2016); it does so by interfering with both nutrient uptake and translocation to the shoot (Perez-Alfocea et al.,2000).

Xylem sap content analysis through stem exudate has been widely known for some time (Vaadia, 1960), used for decades (e.g. Ferrario et al.,1992;
Urrestarazu et al., 1996b; Kato et al., 2001; Masuda et al., 2001; Rep et al., 2003; Yamasaki, 2003) and still today (Ariga et al., 2014) for herbaceous plants. For these plants, their daily variations have been studied (e.g. Wallace et al., 1966; Schurr and Schulze, 1995; Urrestarazu et al., 1996a, 1996b), as well as the effect of salinity on their ionic composition (Perez-Alfocea et al., 2000). 
Root-to-shoot signaling via xylem sap has been reported as an important mechanism by which plants respond to stress (Fernández-García et al., 2011). Therefore, the flow rate and chemical composition of xylem sap have been reported as indicators of root activity or root health under field conditions (e.g. Engels et al., 2000; Morita et al., 2000; Yamasaki, 2003).

Among the anions present in the xylematic flow, nitrate is of those in highest concentrations. Additionally, nitrates are usually the most representative of nitrogen compounds circulating through the xylem sap from root to shoot (Goto et al., 1987). In terms of majority cations in xylem sap, $\mathrm{K}^{+}$is present; however, there is not much information on its concentration or variation in different environmental conditions.

There is little information on the effect of salinity on nitrate and potassium contents in xylem sap.

The objective was to determine the nitrate and potassium contents in xylem sap and the root-shoot transportation of both as a function of the salinity of the nutritional solution provided.

\section{Materials and Methods}

\subsection{Plant growth and treatments}

Tomato seeds (cv. Gold Era) were sown January 1st, 2015, with seedling trays filled with Pelemix ${ }^{\circledR}$ coconut fiber as described by Morales and Urrestarazu (2013) with an alveolar volume of $50 \mathrm{~cm}^{3}$, and were given a solution similar to that described by Sonneveld and Straver (1994) in order to establish an EC of $2.2 \mathrm{dS} \mathrm{m}^{-1}$ as the control group.

Once the seedlings had reached a state with 4 true leaves, the treatments were applied. These treatments consisted of fertigation of nutritional solutions for which their electrical conductivities were measured at 2.2, 3.5, 4.5, 6 and $12 \mathrm{dS} \mathrm{m}^{-1}$. These EC increments in the solution were achieved by means of a mother solution with macronutrient concentrates, while the proportions of micronutrients remained constant through further mixing. The $\mathrm{pH}$ of the nutritional solutions also remained at a level of 5.8 with the addition of diluted nitric acid.

\subsection{Collection of xylem sap}

The xylem sap was obtained after cutting incisions in the leaves of the cotyledons that had been eliminated. The stalks were incised following a procedure similar to the one described in Masuda et al. (2001) and in Gil de Carrasco et al. (1994). The incision on the stalk was performed at noon, according to the criteria set by Urrestarazu et al. (1996a, 1996b).

A silicone tube was fixed over the stump of mesocotyl, and the exudate was removed by means of a microaspirator. The volume was measured with a calibrated micro-syringe. $\mathrm{pH}$ and $\mathrm{EC}$ were measured using a pH-meter and an EC-meter with microelectrode, respectively. The xylem exudate was centrifuged for $10 \mathrm{~min}$ at 3000 $\mathrm{g}$, and the floating solution was recovered and stored in $1.5 \mathrm{~mL}$ Eppendorf tubes and frozen until analysis.

\subsection{Ion analysis}

For ion analysis, $\mathrm{NO}_{3}^{-}$and $\mathrm{K}^{+}$were diluted and measured by ionic chromatography, and injected into a Dionex-2000i/sp with AS12 anionic and CS12 cationic columns, respectively, as described by Gil de Carrasco et al.(1994).

\subsection{Statistical analysis}

The experimental design was performed by means of a random system of complete plots, with four plots per condition. Each block contained 15 plants. 
Statistical analyses were conducted with Statistical Products and Service Solutions Software for Windows, and the software packages used were Statgraphics Centurion ${ }^{\circledR}$ 16.06.15 and Microsoft Office 2010. Data were analyzed with analysis of variance (ANOVA), and differences between the means were tested using Tukey's test $(P \leq 0.05)$.

\section{Results and Discussion}

\subsection{Xylematic Flow, Xylem sap EC and $p H$}

A highly significant effect on xylematic flow was detected due to the increment of salinity in the nutritional solution (Figure 1A).
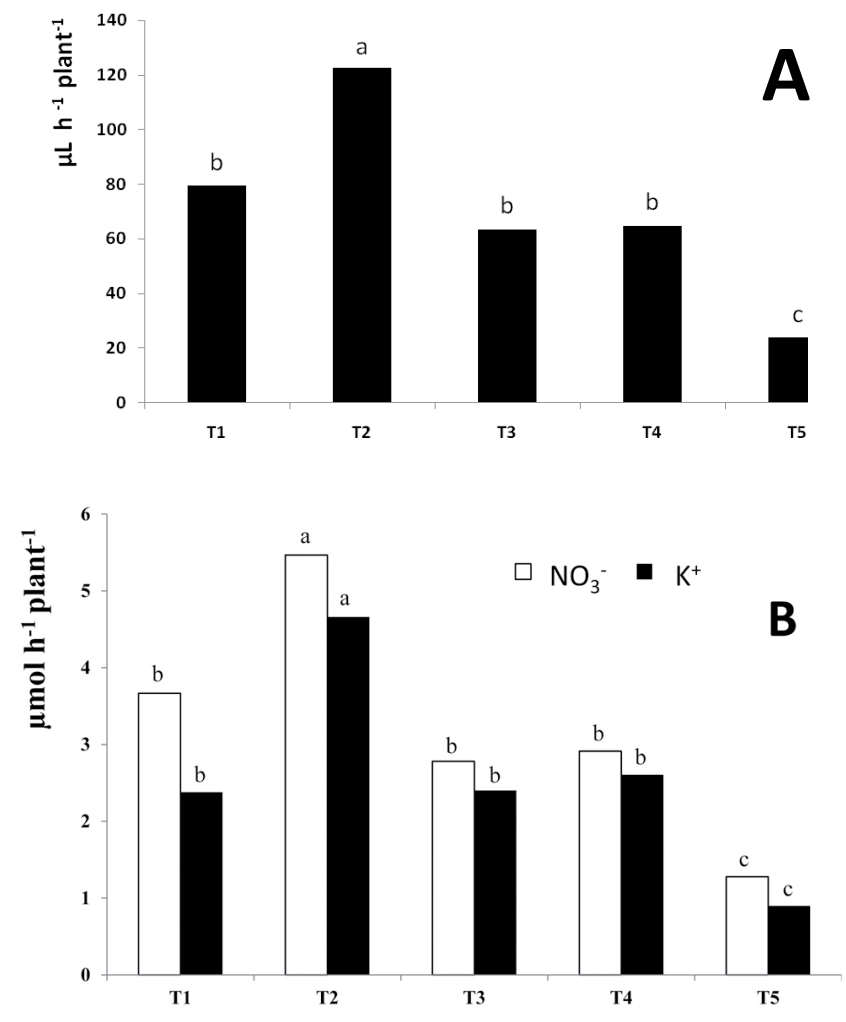

Figure 1. Xylem sap volume (A), nitrate and potassium flux (B) as a function of the salinity of the nutritional solution supply. T1, T2, T3, T4, and T5 are treatments of EC for 2.2, 3.5, 4.5, 6.0 and $12.0 \mathrm{dS} \mathrm{m}^{-1}$, respectively. Different letters indicate significant differences at $P \leq 0.05$ (Tukey test). 
The maximal flow was $123 \mu \mathrm{L} \mathrm{h}^{-1}$ plant $^{-1}$ for $\mathrm{T} 2$, which is $80 \%$ more volume over the plot with the highest EC (T5), and 50\% more than the rest of the conditions (T1, T3, and T4). The xylematic flow data coincide with those reported by White et al. (1981) and Urrestarazu et al. (1996a, 1996b). The behavior of an optimal flow for a determined $\mathrm{EC}$ range, with a minimum threshold and maxima above and below, coincides with the model proposed by Sonneveld and Vooght (2009), which was in turn derived from the classical Maas and Hoffman (1977) model for crop yield in relation to the EC of the nutritional solution or rhizosphere (Figure 2).

The xylem sap $\mathrm{pH}$ was shown to have no significant differences among the groups, rather hovering between 5.08 and 6.02 (Figure 3A). Similar exudate $\mathrm{pH}$ values from young tomato plants have been reported from between 5.56 and 6.13 (e.g. Gil de Carrasco et al., 1994; Else et al.,
1995; Urrestarazu et al., 1996a), although higher values, from 6.45 to 6.50 , have been reported for nighttime extracts (White et al., 1981), we found similar values in all cases for the different saline treatments tested, probably to maintenance the appropriate values for xylem sap, as it is well known -for example- that metal solubility, dissociation constants, hydrolysis reactions and metal binding in general are all $\mathrm{pH}$-dependent (White et al., 1981). The EC of the xylem saps varied from 5.2 to $7.6 \mathrm{dS} \mathrm{m}^{-1}$ (Figure 3B); the highest values were obtained from group $\mathrm{T} 5$, and the minimum, from $\mathrm{T} 1$ and $\mathrm{T} 2$. Although the EC of the nutritional solution increased by $9.8 \mathrm{dS} \mathrm{m}^{-1}$, the xylem sap itself only increased by $3.6 \mathrm{dS} \mathrm{m}^{-1}$. As such, the EC in the plants remained much more stable than that of the existing rhizosphere variation, which implies a significant level of metabolic regulation for EC in xylem sap, described from very old since the decade of the 80s (White et al., 1981).

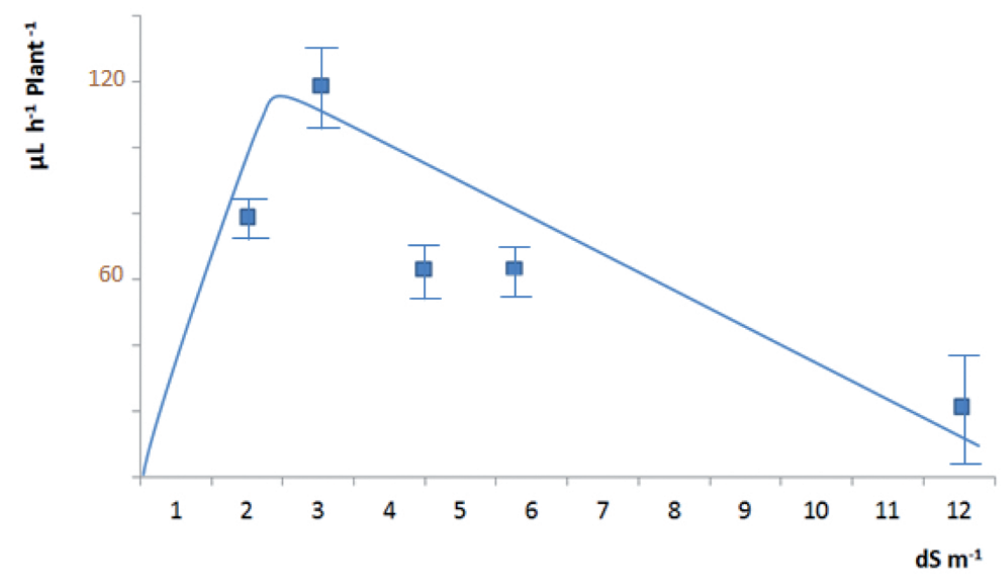

Figure 2. Xylematic flux for tomato seedlings, adjusted to the model from Sonneveld and Voogt (2009) for production as a function of electrical conductivity of the nutritional solution. 

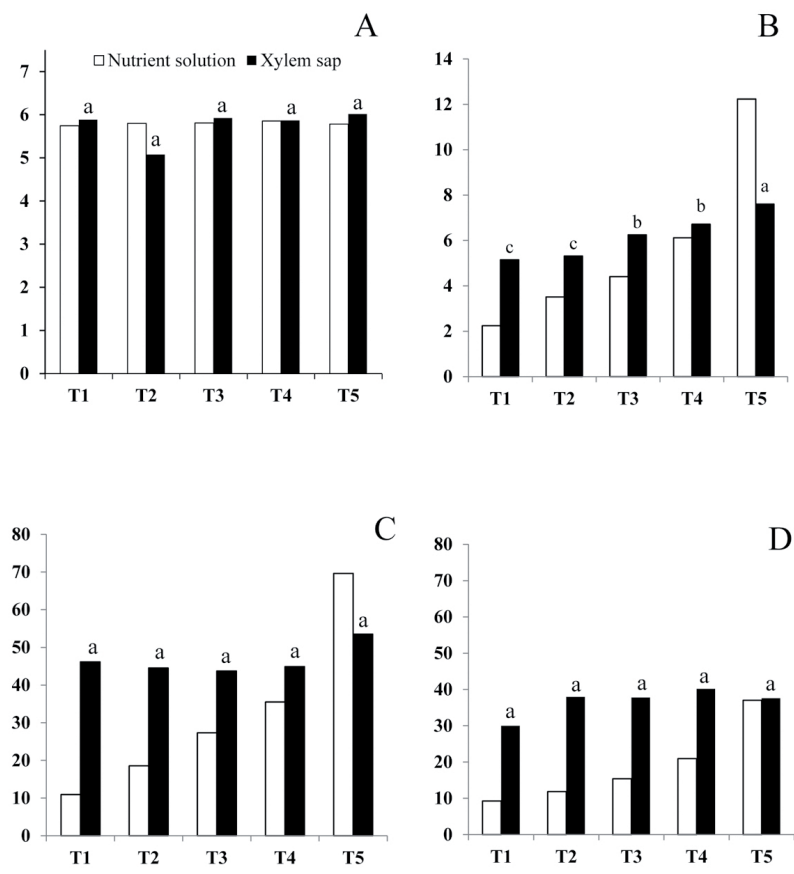

Figure 3. Values for $\mathrm{pH}(\mathrm{A}), \mathrm{EC}\left(\mathrm{dS} \mathrm{m}^{-1}\right)(\mathrm{B})$, and $\mathrm{NO}_{3}-(\mathrm{C})$ and $\mathrm{K}^{+}(\mathrm{D})$ content $\left(\mathrm{mmol} \mathrm{L}^{-1}\right)$ in xylem sap flux as a function of the salinity of the nutritional solution supplied. T1, T2, T3, T4, and T5 are the treatment of EC for 2.2, 3.5, 4.5, 6.0 and $12.0 \mathrm{dS} \mathrm{m}^{-1}$, respectively. Different letters indicate significant differences at $P \leq 0.05$ (Tukey test).

\subsection{Xylem $\operatorname{sap} \mathrm{NO}_{3}^{-}$and $\mathrm{K}^{+}$}

Although the $\mathrm{NO}_{3}^{-}$concentration was increased progressively to almost seven times the original value in the nutritional solution (Figure $3 \mathrm{C}$ ), the $\mathrm{NO}_{3}^{-}$concentration in the xylem sap remained constant at around $50 \mathrm{mM}$; indeed, there were no significant differences between any of the groups. Masuda (1989) and Masuda and Shimada (1993) had already reported similar concentrations for nitrates found in sap although the external concentration was much higher, and Goto et al. (1987) also concluded that, with and without additional external fertilization for groundnut plant, the nitrate concentration in xylem sap remained the same. On the other hand, Bialczyk et al.(2004) found that the concentration of nitrates and ammonium is dependent on the proportion of these in the cultivation media.

The $\mathrm{K}^{+}$concentration in the xylem sap was between 30 and $40 \mathrm{mM}$ (Figure 3D), again without statistically significant differences. Masuda (1989) and Perez-Alfocea et al.(2000) reported a somewhat lesser potassium level $(20 \mathrm{mM})$. The tendency for potassium was similar to that of $\mathrm{NO}_{3}^{-}$, and remained constant independently of increases in the rhizosphere; reflecting this, similar reports from the works of Perez-Alfocea et al. (2000) found $\mathrm{K}^{+}$concentration stability by 
increased exposure time to greater salinity. As for our case, the $\mathrm{K}^{+}$concentration stability in the xylem sap was achieved by the incrementally increased saline concentration with all the macronutrients.

\subsection{Long way transport}

Considering the average concentration of $\mathrm{K}^{+}$and $\mathrm{NO}_{3}{ }^{-}$nutrients, and the rate of xylem sap flow, Figure $1 \mathrm{~B}$ shows the transport between root and shoot. There is a similar tendency between both ions being transported. Although the concentration of both ions in the xylem sap is constant, flow is the predominant factor; and since flow is highly variable as a function of the EC of the nutrition solution, the final result is highly significant, wide variation in the root-shoot ascendant transport. Treatment T2 significantly transported 56\% more $\mathrm{NO}_{3}^{-}$and $\mathrm{K}^{+}$did treatments $\mathrm{T} 1, \mathrm{~T} 3$, or $\mathrm{T} 4$. The most saline treatment, $\mathrm{T} 5$, reduced the transportation of these ions by up to $50 \%$ with respects to T1, T3, and T4. This implies that the reduction of transport of these elements as much as $\mathrm{NO}_{3}^{-}$a long distance from the root to shoot is mainly due to a decrease in volume of xylem flow. This work is studied the major cation and anion macronutrient (Potassium and Nitrate), but probably this general roles can be extrapolate to other macronutrient under its ionic nutrient fertilizer like Calcium, Phosphate or Sulfate inside xylem transport. This behavior is showing the same as that modeled by Sonneveld and Voogt (2009) for the correlation between EC and yield.

\section{Conclusions}

The concentration of nitrates and potassium in xylem sap remained constant, while the external rhizosphere concentration varied greatly in terms of $\mathrm{EC}$, between 2.2 and $12.0 \mathrm{dS} \mathrm{m}^{-1}$. Nevertheless, since the xylematic flow was strongly affected by this incremental EC in the nutritional solution, long distance root-shoot transportation of these ions increased significantly, with a gap of up to $80 \%$ of both $\mathrm{NO}_{3}{ }^{-}$and $\mathrm{K}^{+}$for $\mathrm{EC}$ from 3.5 to $12 \mathrm{dS} \mathrm{m}^{-1}$.

\section{Acknowledgements}

The authors gratefully acknowledge the support of Mexican National Council for Science and Technology (CONACYT) for its financial support for this work.

The authors gratefully acknowledge the support of CONICYT through Project FONDECYT INITIATION INTO RESEARCH 2014 nº 11140154.

\section{References}

Ariga, T., Hazama, K., Yanagisawa, S., Yoneyama, T. 2014. Chemical forms of iron in xylem sap from graminaceous and non-graminaceous plants. Soil Sci Plant Nutr. 60, 460-469.

Bialczyk, J., Lechowski, Z., Dziga, D. 2004. Composition of the xylem sap of tomato seedlings cultivated on media with $\mathrm{HCO}_{3}{ }^{-}$and nitrogen source as $\mathrm{NO}_{3}^{-}$or $\mathrm{NH}_{4}^{+}$.Plant and Soil. 263, 265-272.

Else, M.A., Hall, K.C., Arnold, G.M., Davies, W.J., Jackson, M.B. 1995. Export of abscisic-acid, 1-aminocyclopropane-1-carboxylic acid, phosphate, and nitrate from roots to shoots of flooded tomato plants - accounting for effects of xylem sap flow-rate on concentration and delivery. Plant Physiol. 107, 377-384.

Engels, C., Neumann, G., Gahoonia, T.S., George, E., Schenk, M. 2000. Assessing the ability of roots for nutrient acquisition. In Root Methods: A Handbook. Eds. Smit AL, Bengough AG, Engels C, Noordwijk M van, Pellerin S and van de Geijn SC, Springer, Berlin, pp: 403-459. 
Fernández-García, N., Hernández, M., Casado-Vela, J., Bru, R., Elortza, F., Hedden, P., Olmos, E. 2011. Changes to the proteome and targeted metabolites of xylem sap in Brassica oleracea in response to salt stress. Plant Cell Environ. 34, 821-836.

Ferrario, S., Agius, I., Morisot, A. 1992.Daily variations of the mineral-composition of xylemic exudates in tomato. J Plant Nutr. 15, 85-98.

Gil de Carrasco, C., Guzmán, M., Lorente, F.A., Urrestarazu, M. 1994. Xylem sap extraction: a method. Commun Soil Sci. Plan. 25, 1829-1839.

Goto, S., Inanaga, S., Kumazawa, K. 1987. Xylem Sap Composition of Nodulated and Non-Nodulated Groundnut Plants. Soil Sci Plant Nutr. 33, 619-627.

Kato, C., Ohshima, N., Kamada, H., Satoh, S. 2001. Enhancement of the inhibitory activity for greening in xylem sap of squash root with waterlogging. Plant Physiol. Bioch. 39, 513-519.

Maas E.V., Hoffman, G.J. 1977. Crop salt tolerance: Current assessment. J. Irrig. Drain E-ASCE.103, 115-134.

Mastrogiannidou, E., Chatzissavvidis, C., Antonopoulou, C., TsabardoukasV.,Giannakoula, A. Therio, I. 2016. Response ofpomegranatecv. wonderful plants to salinity. J. Soil Sci. Plant Nutr. 16 (3), 621-636.

Masuda, M. 1989. Mineral Concentrations in Xylem Exudate of Tomato and Cucumber Plants at Midday and Midnight.J. Japan Soc.Hortic. Sci. 58, 619-625.

Masuda, M., Shimada, Y. 1993. Diurnal changes in mineral concentrations of xylem exudate in tomato plants and their concentrations as affected by sunlight intensity and plant ages. J JPN Soc. Hortic. Sci. 61, 839-845.

Masuda, S., Kamada, H., Satoh, S. 2001. Chitinase in cucumber xylem sap. Biosci Biotech Bioch. 65, 1883-1885.
Morales, I., Urrestarazu, M. 2013. Thermography Study of Moderate Electrical Conductivity and Nutrient Solution Distribution System Effects on Grafted Tomato Soilless Culture. Hortscience. 48, 1508-1512.

Morita, S., Okamoto, M., Abe, J., Yamagishi, J. 2000. Bleeding rate of field-grown maize with reference to root system development. JPN J. Crop Sci. 69, 80-85.

Perez-Alfocea, F., Balibrea, M.E., Alarcon, J.J., Bolarin, M.C. 2000. Composition of xylem and phloem exudates in relation to the salt-tolerance of domestic and wild tomato species. J. Plant Physiol. 156, 367-374.

Rameeh, V. 2012. Ions uptake, yield and yield attributes of rapeseed exposed to salinity stress. J. Soil Sci. Plant Nutr.12 (4), 851- 861.

Rep, M., Dekker, H.L., Vossen, J.H., De Boer, A.D., Houterman, P.M., De Koster, C.G., Cornelissen, B.J.C. 2003. A tomato xylem sap protein represents a new family of small cysteine-rich proteins with structural similarity to lipid transfer proteins. Febs. Lett. 534, 82-86.

Schurr, U., Schulze, E.D. 1995. The concentration of xylem sap constituents in root exudate, and in sap from intact, transpiring castor bean-plants (Ricinuscommunis L). Plant Cell Environ. 18, 409-420.

Sonneveld, C., Straver, N. 1994. Voedingsoplossingen voor groenten en bloemengeteeld in water of substraten [Nutrient solutions for vegetables and flowers grown in water or substrates].10th ed. Proefstation voor Tuinbouwonder Glas, Naaldwijk.

Sonneveld, C., Voogt, W. 2009. Plant nutrition of Greenhouse crops. Springer, Dordrecht, The Netherlands, pp: 431.

Urrestarazu, M., Sánchez, A., Lorente, F.A., Guzmán, M. 1996a.A daily rhythmic model for $\mathrm{pH}$ and volume from xylem sap of tomato plants.Commun Soil Sci. Plan. 27, 1859-1874. 
Urrestarazu, M., Sánchez, A., Lorente, F.A., Guzmán, M. 1996b.Chronophysiological rhythm model for daily ionic variation of xylematic exudates in tomato plants.Commun Soil Sci. Plan. 27, 18431858.

Vaadia, Y. 1960. Autonomic diurnal fluctuations in rate of exudation and root pressure of decapitated sunflower plants. Physiol. Plantarum. 13, 701717.

Wallace, A., Ashcroft, R.T., Lunt, O.R. 1967. Daynight periodicity of exudation in detopped tobacco. Plant Physiol. 42, 238-242.
White, M.C., Decker, A.M., Chaney, R.L. 1981. Metal complexation in xylem fluid .1.chemical-composition of tomato and soybean stem exudate. Plant Physiol. 67, 292-300.

Yamasaki, A. 2003. Root-pressure driven xylem sap flow in greenhouse melon (Cucumismelo L.): diurnal change and the effects of shading, growth stage, rootstock and fruit number. Plant Soil. 255, 409-412. 